\title{
TURNING PEOPLE INTO WORKBOOKS
}

With its third biannual conference, RTD 2017 continued to mix intimacy and ambition, with lively and informal discussion of research through design enabled by a focus on the artefacts that come about through research projects. The National Museum of Scotland in Edinburgh acted as a hosting venue for the programme, which complemented the organisers ambition to see design outcomes set against the material archive. Outside of the sessions I took part in, I joined other panellists for a fairly wide ranging discussion on what the future of research through design meant for them. One question that has been particularly productive was about the articulation of research in commercial settings.

To keep our opening statements concise, panellists were asked for a single image. I broke the brief by taking a spread from a book that will soon be published by Mattering Press depicting the pages of a workbook that was put together for ECDC (Energy and Co-Designing Communities), a three year Research Councils UK funded project. Our group at Goldsmiths' Interaction Research Studio was one of seven research clusters looking at the effects of a Government scheme where the Department of Energy and Climate Change funded around 20 communities across the UK to undertake energy demand reduction measures. The research groups took a range of approaches to interpret what these communities were doing. Ours was to design a technical platform, developing the methodology of the Studio, that has variously been described as ludic, speculative, or inventive.

\section{HOW WE USED WORKBOOKS}

In the Studio we use workbooks as a method for synthesising material generated during fieldwork. We had spent a fair chunk of time with different energy reduction groups across the UK, including tours of infrastructure such as wind turbines, photovoltaics and ground source heat pumps. We heard about the ambitions of these groups, about environmental predictions, the politics of delivering these projects, the relationship between different constituencies in each setting. Workbooks allowed us to bring together documentation of these different encounters, and also other kinds of material, from reviews of literature and practice. Through the synthesis of disparate material into a workbook, as researchers we share and reflect on perspectives. This in turn supports the materialisation of topics and we begin to understand design options and possibilities. In this way, making and sharing workbooks is an internal process, supporting activity in the studio.

\section{THE ISSUE WITH WORKBOOKS}

My aim was to use the image of the workbook pages to bring to RTD an issue that I haven't yet resolved. I had taken the workbook to a meeting with one of our demand reduction groups. It was unusual for us to show a workbook to respondents, though given the extended timescales of our research in relation to the schedule of this group, I thought it would be interesting to take along a document showing research activity. However, looking through the book together was a slightly odd situation, like taking an early draft of fiction to people who recognise themselves in the characters or dialogue. For example, a page titled "the champions" depicting a rosette was a reflection on competition and reward as a recurring feature of sustainability programmes. Elsewhere, Futures Tourism reimagined wind turbine farms, with their associated planning issues, as a future tourist destination, represented here by electricity pylon spotters. The situation was odd in several ways, partly tied to anxiety about assuming authorship of others' accounts, also the seemingly insubstantial way in which the images depicted deeply held beliefs, though overall brought about through anticipating responses from these unplanned readers. While I would argue with conviction for the rigour and earnestness of our research approaches, the depictions in workbooks necessarily reduce the thickness of our data to support the accretion of detail into design elements.

So why did I hope a retelling of this awkward episode would be useful? While taking studio process into the settings on which they were based was somewhat uncomfortable, it was also productive. First and foremost it supported me as a researcher in thinking through the tensions of treating the commitments of others speculatively. This episode also helped me consider how our practices have rhythms where the action of practice shifts, between letting others provide accounts of their situations, and transformations of those accounts into artefacts that speak for others. And I wonder, is there scope, within our analytical accounts of practice, to attend to these moments when our articulations come under pressure? 